\title{
MAPA CONCEITUAL COMO ESTRATÉGIA DE ENSINO DAS TECNOLOGIAS DAS EDIFICAÇÕES
} APLICATION OF CONCEPTUAL MAP AS A TEACHING STRATEGY FOR BUILDING TECHNOLOGIES

Leonete Cristina de Araújo Ferreira Medeiros Silva ${ }^{1}$

DOI: 10.37702/REE2236-0158.v40p343-352.2021

\section{RESUMO}

No contexto desafiador da docência do ensino superior na Engenharia, foi escolhida a metodologia de aprendizagem ativa Mapa conceitual para utilização no ensino da disciplina de Tecnologia das Edificações, para alunos do curso de Bacharelado em Engenharia Civil em uma universidade pública no semiárido nordestino. Essa metodologia se baseia na aprendizagem significativa do aluno e, devido à sua flexibilidade, pode ser empregada em várias situações do ensino. No presente caso, foi utilizado como recurso de aprendizagem para o conteúdo de Fundações e Contenções e como processo de avaliação para o conteúdo Alvenaria de Vedação de Blocos Cerâmicos, em uma mesma turma, em dois semestres consecutivos. Os mapas foram analisados em função do atendimento às expectativas do professor, dos conceitos a serem trabalhados e das relações entre eles, da escolha do tipo de mapa e da apresentação gráfica a partir do uso do CMapTools®. Os tipos mais empregados foram teia de aranha e hierárquico, respectivamente. A maioria dos mapas foram considerados ACEITOS e apresentaram resultado gráfico satisfatório com emprego da ferramenta indicada.

Palavras-chave: aprendizagem ativa; tecnologia das construções; Ensino de Engenharia.

\begin{abstract}
In the didactic context of higher education teaching, the methodology of formatting a specialization course in Communication Sciences was used. This methodology is based on meaningful student learning and, because of its flexibility, can be used on a few teaching occasions. In this case, it was used as a learning resource for the content of "Foundations and Containers" and as an evaluation process for the content "Masonry of Ceramic Block Fencing" in the same class. The maps were invited according to the fulfillment of the teacher's expectations between the concepts, the type choice and the graphic presentation of the use of CMapTools ${ }^{\circledR}$. The most used types were spider web and hierarchical, respectively. Most of the maps were consumed and successfully used chart in an indicated machine.
\end{abstract}

Keywords: active learning; construction technology; engineering teaching.

\section{INTRODUÇÃO}

$\mathrm{Na}$ atualidade, cada vez mais, percebe-se a necessidade da atualização curricular e do projeto pedagógico dos cursos de Engenharia para atendimento às Diretrizes Curriculares Nacionais vigentes. Assim, atender o perfil do formando do curso de Engenharia Civil confere à docência no Ensino Superior um caráter desafiador.

\footnotetext{
${ }^{1}$ Doutoranda em Engenharia Química - UFRN. Professora - UFERSA, Departamento de Engenharias, Centro Multidisciplinar de Caraúbas, leonete.cristina@ufersa.edu.br
} 
$\mathrm{O}$ processo educativo envolve democratizar o espaço da sala de aula, que deve ser permeado pela pesquisa, e contribuir de forma ativa para a descoberta e para o desenvolvimento de uma atitude de autonomia intelectual. Nessa ótica, o emprego das metodologias de aprendizagem ativas surge como recurso didático para uma formação crítica e reflexiva do estudante universitário e se lança como uma prática pedagógica inovadora (BORGES; ALENCAR, 2014).

Essas metodologias vêm sendo cada vez mais adotadas pelos currículos de vários cursos no país. O professor é o agente que deve desenvolver situações e condições para o aluno observar, experimentar, comparar, analisar e levantar hipóteses, de modo que seja capaz de avaliar e explicar os problemas práticos (PINTO et al., 2011).

A postura do professor em adotar esse tipo de metodologia envolve uma decisão para contribuir com a formação de profissional voltada para novas demandas de responsabilidades sociais e globais. Atualmente, pode-se dizer que há um processo de transição entre as práticas metodológicas tradicionais e de aprendizagem ativa.

Os mapas conceituais constituem um recurso potencialmente facilitador de uma aprendizagem significativa. Sua aplicação tem proporcionado que os estudantes relacionem os conhecimentos que são trabalhados em diferentes componentes do currículo, tanto os que priorizam o desenvolvimento de habilidades técnicas, quanto os que têm como prioridade o desenvolvimento dos conhecimentos relacionados às humanidades (PINTO et al., 2011).

O Mapa conceitual consiste em uma técnica desenvolvida por Joseph Novak e seus colaboradores na Universidade de Cornell (EUA), baseado na teoria de aprendizagem significativa, que considera uma estruturação hierárquica dos conceitos, tanto através de uma diferenciação progressiva quanto de uma reconciliação integrativa entre eles (TAVARES, 2007). Para este trabalho, a escolha do mapa conceitual como recurso de aprendizagem teve como base a seguinte ideia:
O uso do mapa no processo de aprendizagem de determinado tema, vai ficando claro para o aprendiz, assim como as dificuldades de entendimento desse tema. $\mathrm{O}$ aluno que desenvolve a habilidade de construir seu mapa conceitual enquanto estuda determinado assunto, está se tornando capaz de encontrar autonomamente o seu caminho no processo de aprendizagem. Caso ele não consiga encontrar as respostas nas consultas ao material instrucional, ele ainda assim terá conseguido ter clareza sobre as suas perguntas, e desse modo já terá encaminhado a sua aprendizagem de maneira conveniente e segura. Pois quando se tem clareza das perguntas, ou das dúvidas, é mais fácil procurar ajuda de pessoas mais experientes (TAVARES, 2007, p. 74-75).

O uso do mapa no processo de aprendizagem de determinado tema vai ficando claro para o aprendiz, assim como as dificuldades de entendimento desse tema. $\mathrm{O}$ aluno que desenvolve a habilidade de construir seu mapa conceitual enquanto estuda determinado assunto está se tornando capaz de encontrar autonomamente o seu caminho no processo de aprendizagem. Caso ele não consiga encontrar as respostas nas consultas ao material instrucional, ele ainda assim terá conseguido ter clareza sobre as suas perguntas e, desse modo, já terá encaminhado a sua aprendizagem de maneira conveniente e segura, pois quando se tem clareza das perguntas, ou das dúvidas, é mais fácil procurar a ajuda de pessoas mais experientes (TAVARES, 2007).

Devido à sua flexibilidade, o mapa conceitual pode ser empregado para diferentes finalidades: instrumento de análise do currículo, técnica didática, recurso de aprendizagem, leitura de artigos em jornais e revistas, demonstração de ideias sobre determinado tema e como meio de avaliação.

Aliando o desafio da educação superior à adoção de práticas inovadoras, no desenvolvimento das disciplinas de Tecnologia das Edificações I e II, foram escolhidos dois conteúdos programáticos para utilização de mapas conceituais. Os componentes curriculares estão compreendidos na área de estudo da construção, no curso de Engenharia Civil de uma universidade pública no semiárido nordestino. 


\section{DESENVOLVIMENTO DO ESTUDO E ELABORAÇÃO DE MAPA CONCEITUAL}

O ensino das Tecnologias das Edificações é distribuído ao longo de duas disciplinas, sendo cada uma de 60 horas. Na disciplina Tecnologia das Edificações I, os alunos desenvolvem competências e habilidades para acompanhar as construções desde seu início, a partir do conteúdo Serviços Preliminares até as Estruturas de Concreto Armado. Como continuidade, a disciplina Tecnologia das Construções II segue com Vedações Verticais até a Entrega da Obra. Assim, o presente estudo foi desenvolvido pelo mesmo professor em dois semestres letivos seguidos e aplicado para a mesma turma.

Os conteúdos escolhidos para utilização de mapa conceitual foram: Fundações e Contenções (primeira fase) e Alvenaria (segunda fase). Para execução da primeira fase, ou seja, na disciplina Tecnologia das Edificações I, foi necessário apresentar informações acerca dos mapas conceituais, baseados nos trabalhos desenvolvidos por Tavares (2007) e Godoy (2017).

Os alunos foram orientados a seguir as etapas recomentadas no Fluxograma (Figura 1).
Durante a aula, foi elaborado um esboço de um mapa conceitual sobre um conteúdo já abordado na disciplina, com a ajuda de um aluno voluntário para desenhar graficamente no quadro as relações entre os conceitos propostos pela turma. Tratou-se apenas de um preparativo para que aplicassem essa orientação com o texto sobre Fundações e Contenções (GERBAUER, 2002) que ainda não havia sido abordado no decorrer do curso.

Em seguida foi realizada uma exposição dialogada acerca dos mapas conceituais e, diante da grande variedade de tipos disponíveis, foram exemplificados conforme listados na Tabela 1. Para elaboração dos mapas, foi sugerido o uso do CmapTolls ${ }^{\circledR}$, que foi desenvolvido sob a supervisão do Dr. Alberto J. Cañas do Institute for Human Machine Cognition da University of West Florida e que pode ser adquirido gratuitamente. Tal ferramenta é usada mundialmente em todos as áreas de conhecimento, em especial nas escolas, universidades e organizações governamentais para estudos individuais ou em grupos. Possui interface gráfica e é muito poderoso no compartilhamento de conhecimento.

Figura 1 - Fluxograma para elaboração de Mapa Conceitual

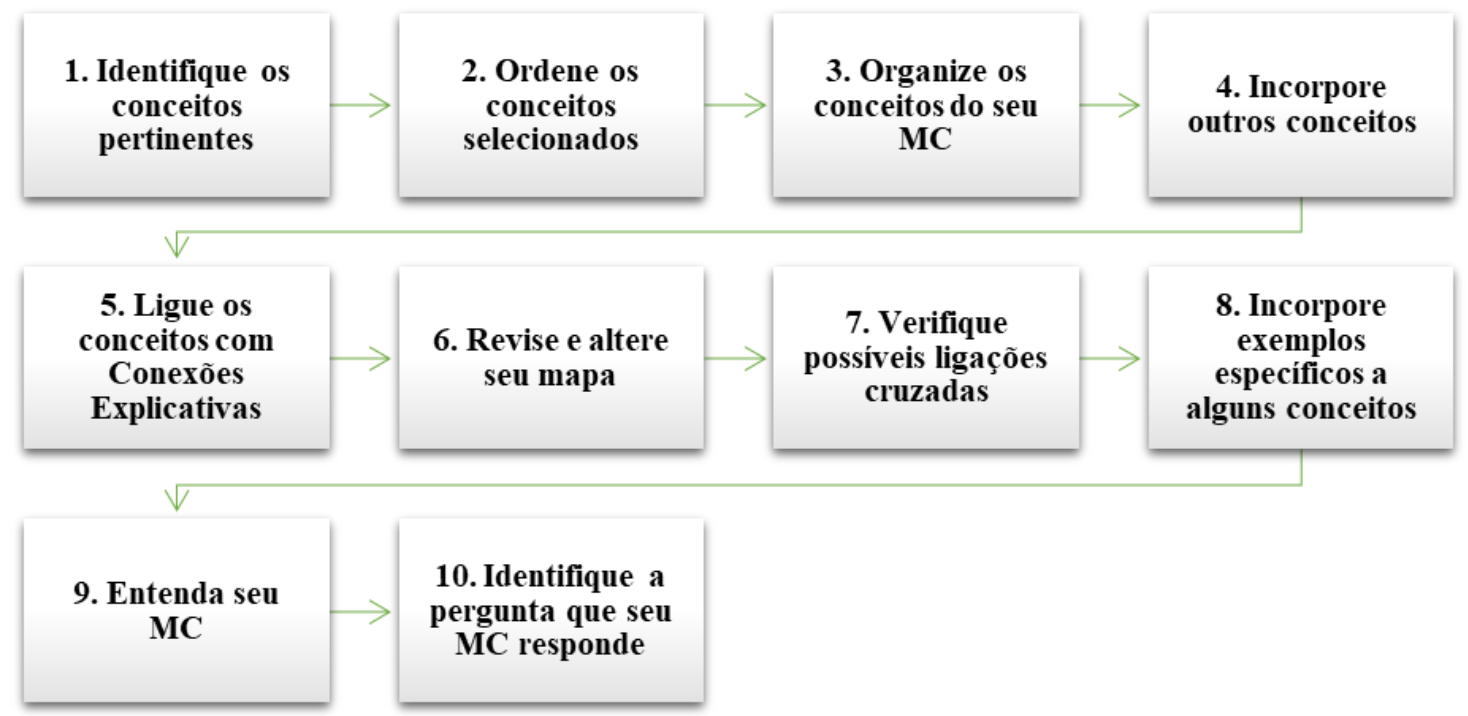

Fonte: adaptada de Godoy (2017). 
Tabela 1 - Alguns tipos de mapas conceituais

\begin{tabular}{|c|c|c|c|}
\hline $\begin{array}{c}{ }^{\circ} \text { Mapa } \\
\text { conceitual }\end{array}$ & Descrição & Vantagens: & Desvantagens: \\
\hline $\begin{array}{l}\text { Tipo teia de } \\
\text { aranha }\end{array}$ & $\begin{array}{l}\text { Coloca-se o conceito } \\
\text { central no meio do } \\
\text { mapa. } \\
\text { Os demais conceitos } \\
\text { vão se irradiando a } \\
\text { partir do centro. }\end{array}$ & $\begin{array}{l}\text { - } \quad \text { Fácil de estruturar. } \\
\text { - Não há preocupação } \\
\text { - com as relações } \\
\text { hierárquicas, ou } \\
\text { transversais. }\end{array}$ & 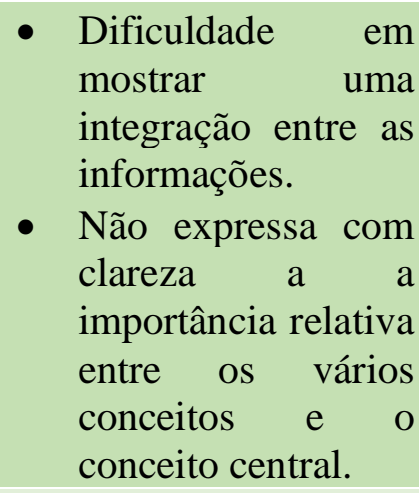 \\
\hline $\begin{array}{c}\text { Tipo } \\
\text { fluxograma }\end{array}$ & $\begin{array}{l}\text { - Organiza } \\
\text { informação de uma } \\
\text { maneira linear. } \\
\text { - Inclui um ponto } \\
\text { inicial e outro ponto } \\
\text { final. }\end{array}$ & $\begin{array}{l}\text { - } \quad \text { Fácil de ler. } \\
\text { - Asinformações } \\
\text { estão organizadas de } \\
\text { uma maneira lógica } \\
\text { e sequencial. }\end{array}$ & 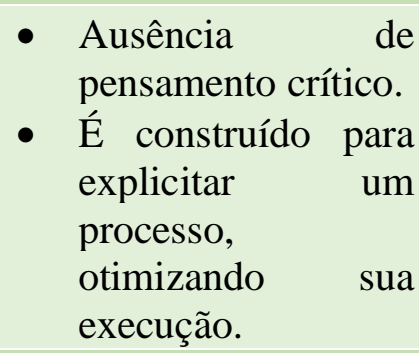 \\
\hline $\begin{array}{l}\text { Tipo sistema: } \\
\text { entrada } \\
\text { e saída }\end{array}$ & $\begin{array}{l}\text { - Organizado como } \\
\text { fluxograma, mas com } \\
\text { o acréscimo da } \\
\text { imposição das } \\
\text { possibilidades } \\
\text { "entrada"e "saída". }\end{array}$ & $\begin{array}{l}\text { - Mostra várias } \\
\text { relações entre os } \\
\text { conceitos. }\end{array}$ & $\begin{array}{l}\text { - Algumas vezes é } \\
\text { difícil de se aplicar. } \\
\text { - Pretende explicar a } \\
\text { transformação de } \\
\text { insumos em produto } \\
\text { acabado. }\end{array}$ \\
\hline Hierárquico & $\begin{array}{l}\text { - Ordem descendente } \\
\text { de importância na } \\
\text { apresentação das } \\
\text { informações. } \\
\text { - A informação mais } \\
\text { importante (inclusiva) } \\
\text { é colocada na parte } \\
\text { superior. }\end{array}$ & 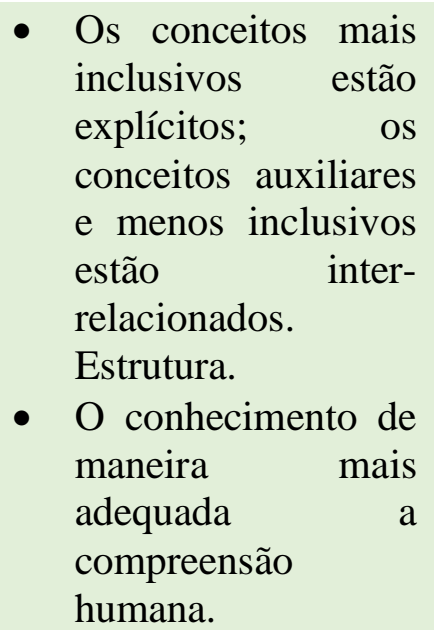 & $\begin{array}{l}\text { - Difícil elaboração, } \\
\text { exige muito } \\
\text { conhecimento } \\
\text { prévio sobre o tema. }\end{array}$ \\
\hline
\end{tabular}

Fonte: adaptada de Tavares (2007).

\section{ANÁLISE DOS MAPAS CONCEITUAIS DESENVOLVIDOS}

Para análise dos mapas propostos, partiu-se do pressuposto de que, de forma geral, não existe regulamento para o traçado de mapas conceituais. O importante é que o mapa seja um instrumento capaz de mostrar significados atribuídos a conceitos e relações entre conceitos no contexto de estudo proposto. Assim, foram avaliados quais os tipos de mapas produzidos, se apresentaram as relações entre conceitos esperadas pelo professor e a apresentação gráfica obtida com o uso da ferramenta CMapTools®.

$\mathrm{Na}$ utilização como recurso de aprendizagem para o conteúdo de Fundações e Contenções os alunos produziram, em sua maioria, mapas tipo teia de aranha, nenhum deles utilizou o tipo sistema: entrada e saída. 
Cerca de $27 \%$ deles conseguiram produzir um mapa hierárquico (Figura 2).

Figura 2 - Tipos de Mapa Conceitual produzidos como Recurso de Aprendizagem

\section{Utilização de Mapa \\ Conceitual como Recurso de Aprendizagem}

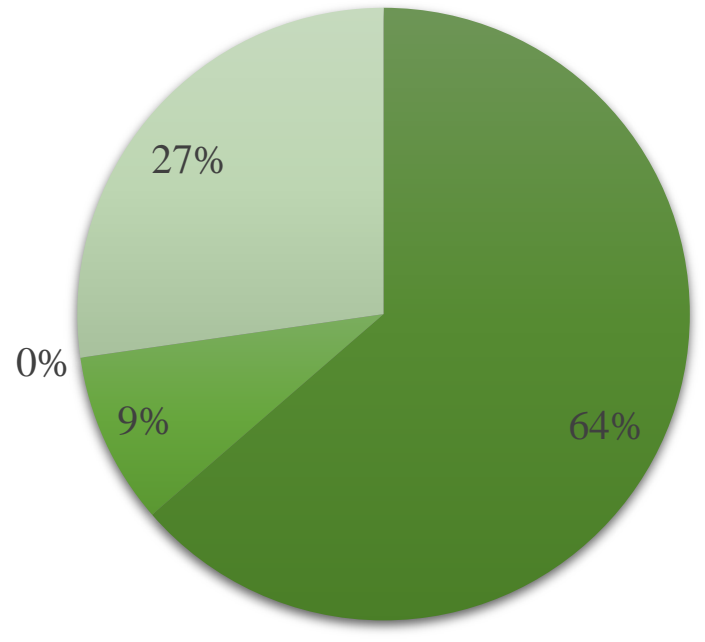

- Tipo Teia de Aranha

- Tipo Fluxograma

- Tipo Entrada e Saída

- Hierárquico

Fonte: elaborada pela autora (2018).

No que diz respeito à expectativa de relação entre os conceitos, verificou-se uma diversidade de mapas produzidos. Uns alunos identificaram e relacionaram poucos conceitos, enquanto outros, diante da quantidade de conceitos identificados, chegaram a subdividir o mapa em mapas complementares, atendendo às orientações da metodologia proposta. $\mathrm{Na}$ Figura 3, verifica-se um mapa conceitual cuja abordagem foi considerada aquém da expectativa. Na Figura 4, pode ser conferido um mapa conceitual com apresentação visual interessante e com mais conceitos incorporados. A Figura 5 mostra o conjunto de mapas com as subdivisões propostas pelo aprendiz.
Como meio de avaliação de aprendizagem, para o conteúdo Alvenaria de Vedação em Blocos Cerâmicos, metade da turma produziu mapas do tipo hierárquico. Esse resultado vai ao encontro da literatura quando esta afirma que esse tipo de mapa requer mais conhecimento prévio sobre o tema (Figura 7).

\section{Figura 3 - Tipos de Mapa Conceitual produzidos} como Processo Avaliativo

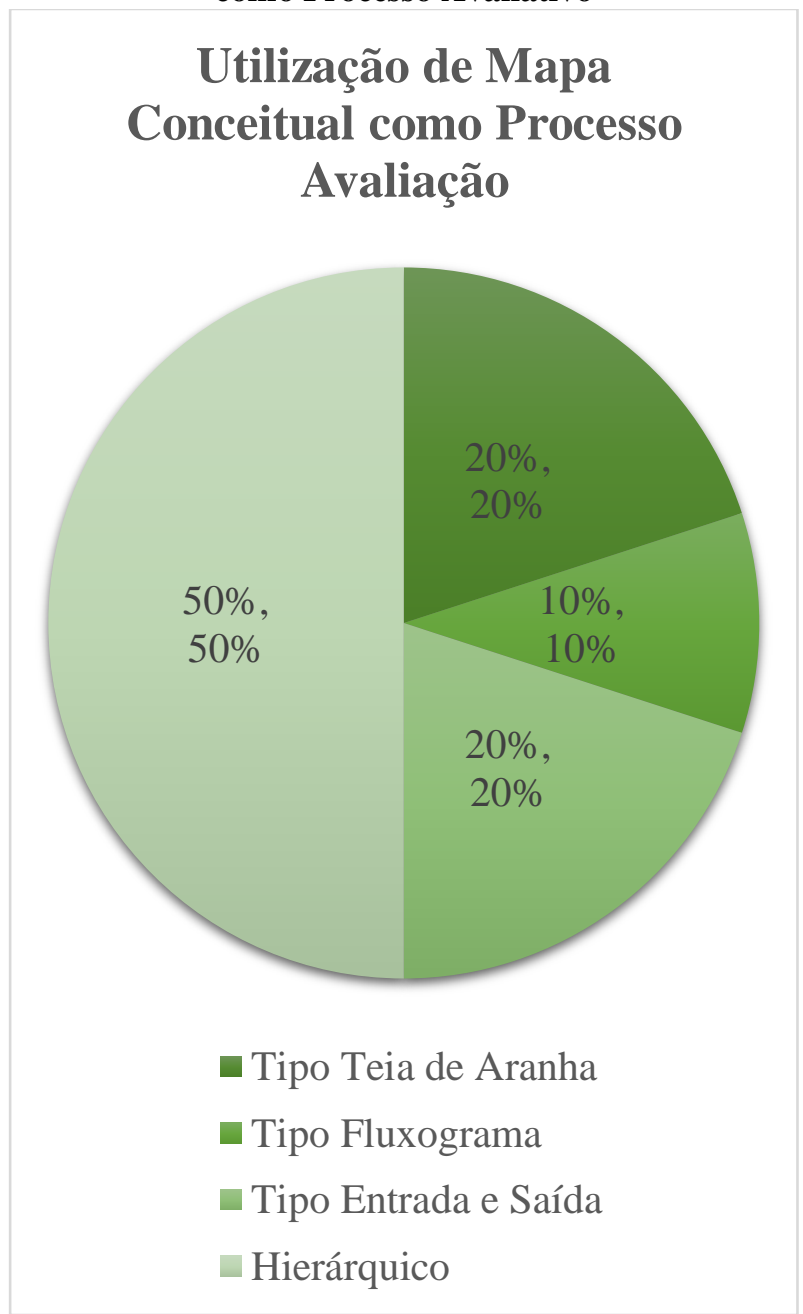

Fonte: elaborada pela autora (2018).

Mais uma vez, percebe-se uma diferença na quantidade de conceitos que cada aluno consegue se apropriar e designar um significado. Nos exemplos mostrados nas Figura 7 e 8, tem-se uma dimensão dos diferentes modos de aprendizagem do conteúdo. 
Figura 4 - Mapa Conceitual sobre Fundações e Contenções produzido pelo aluno A

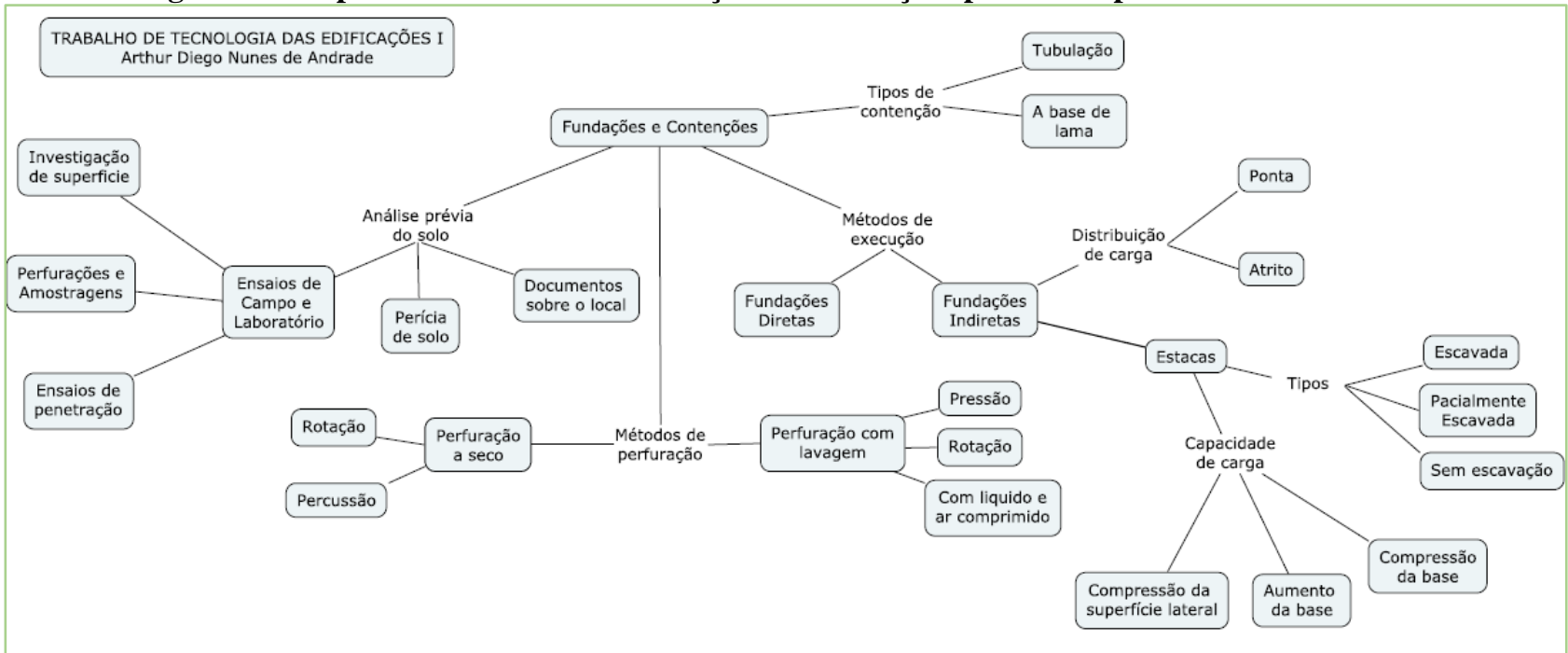

Fonte: aluno A da disciplina Tecnologia das Edificações I (2017).

Figura 5 - Mapa Conceitual sobre Fundações e Contenções produzido pelo aluno B

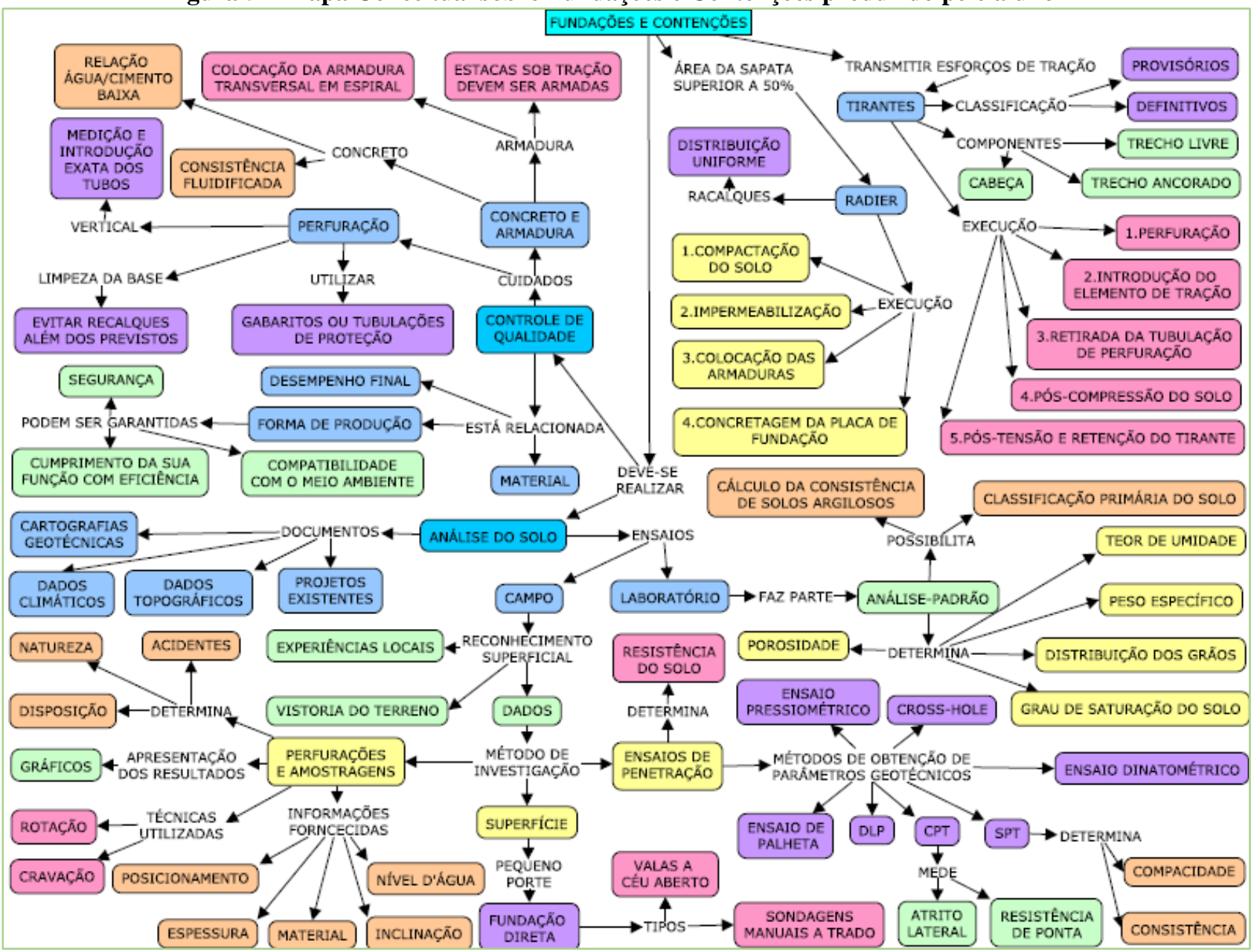

Fonte: aluno B da disciplina Tecnologia das Edificações I (2017). 
Figura 6 - Mapa Conceitual sobre Fundações e Contenções produzido pelo aluno C

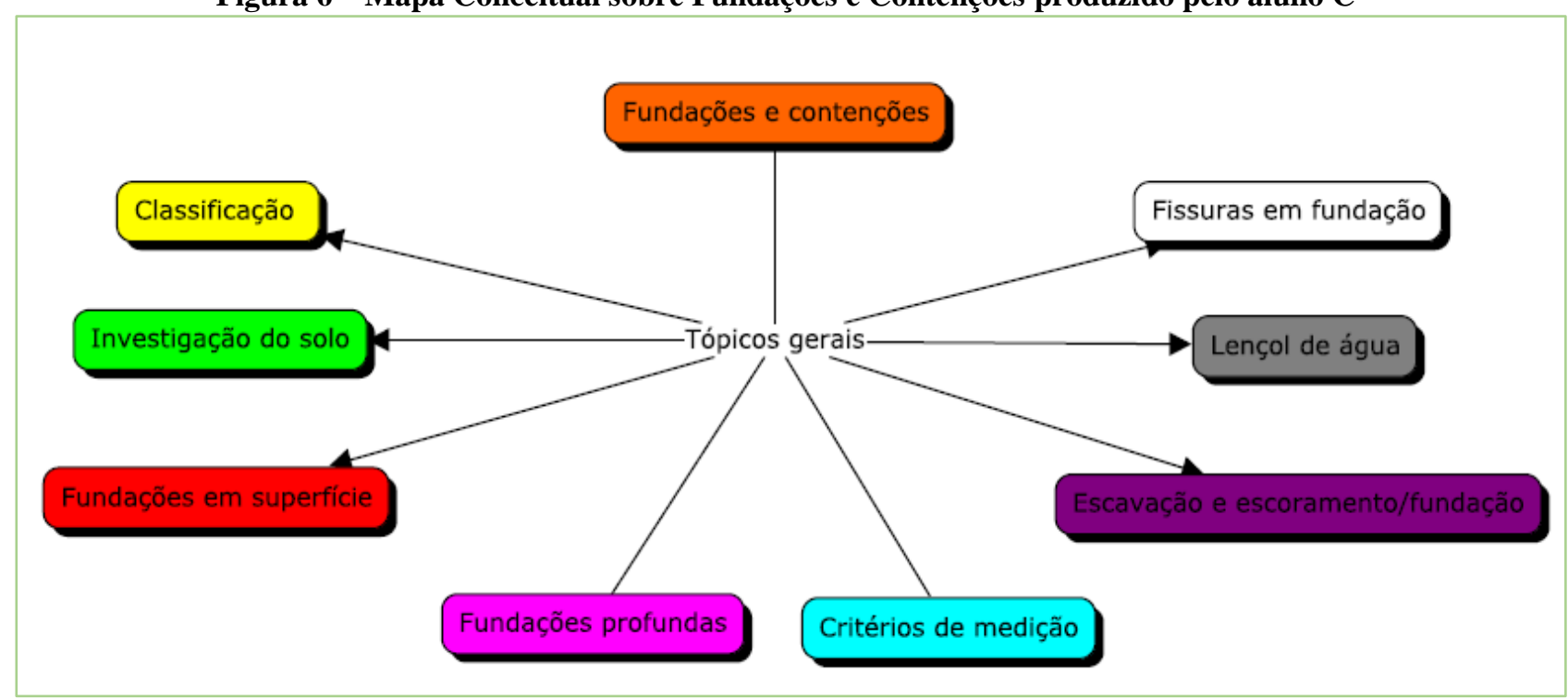

(a)

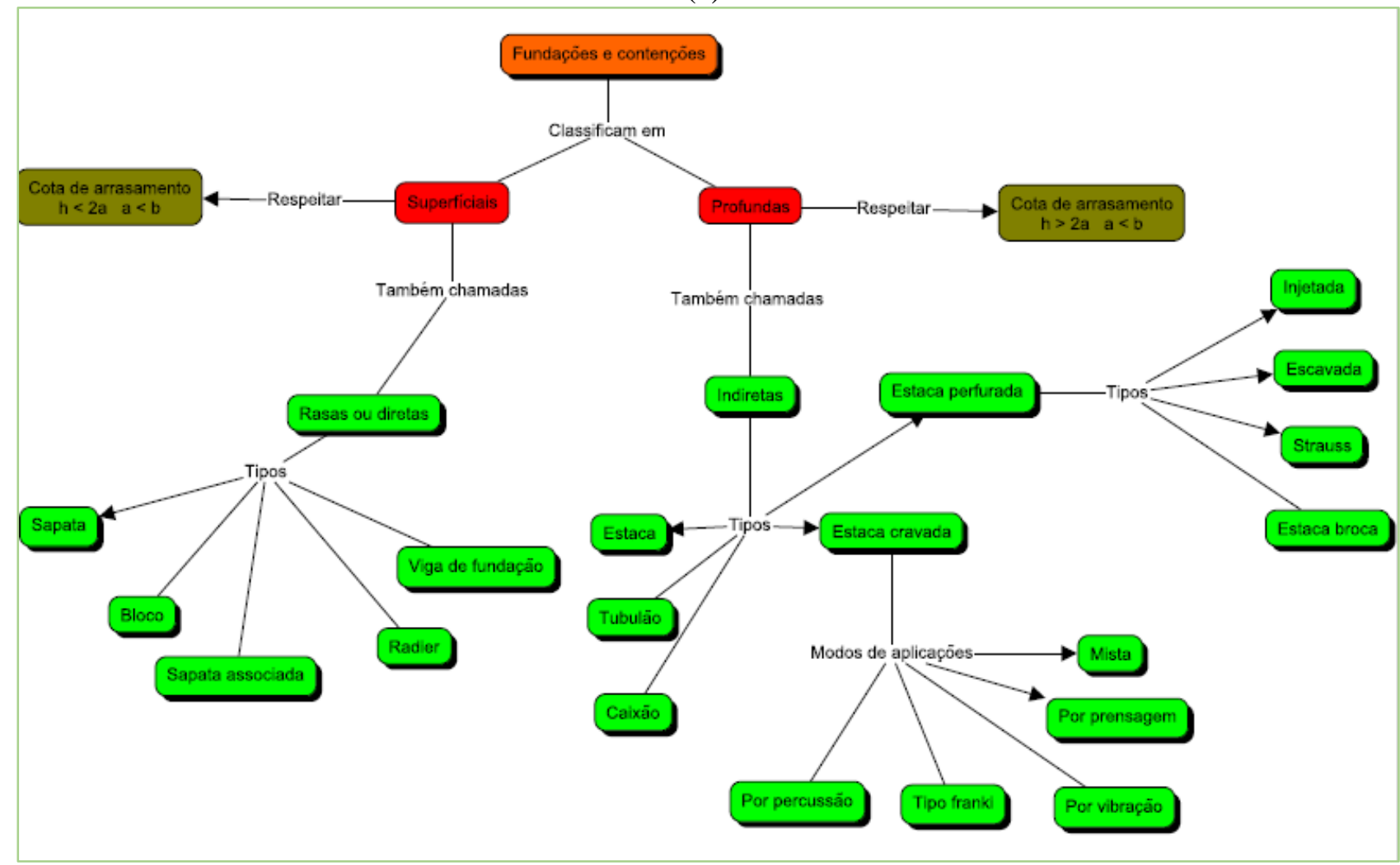

(b)

Fonte: aluno B da disciplina Tecnologia das Edificações I (2017). 
Figura 7 - Mapa Conceitual sobre Alvenaria de Vedação de Bloco Cerâmico produzido pelo aluno A

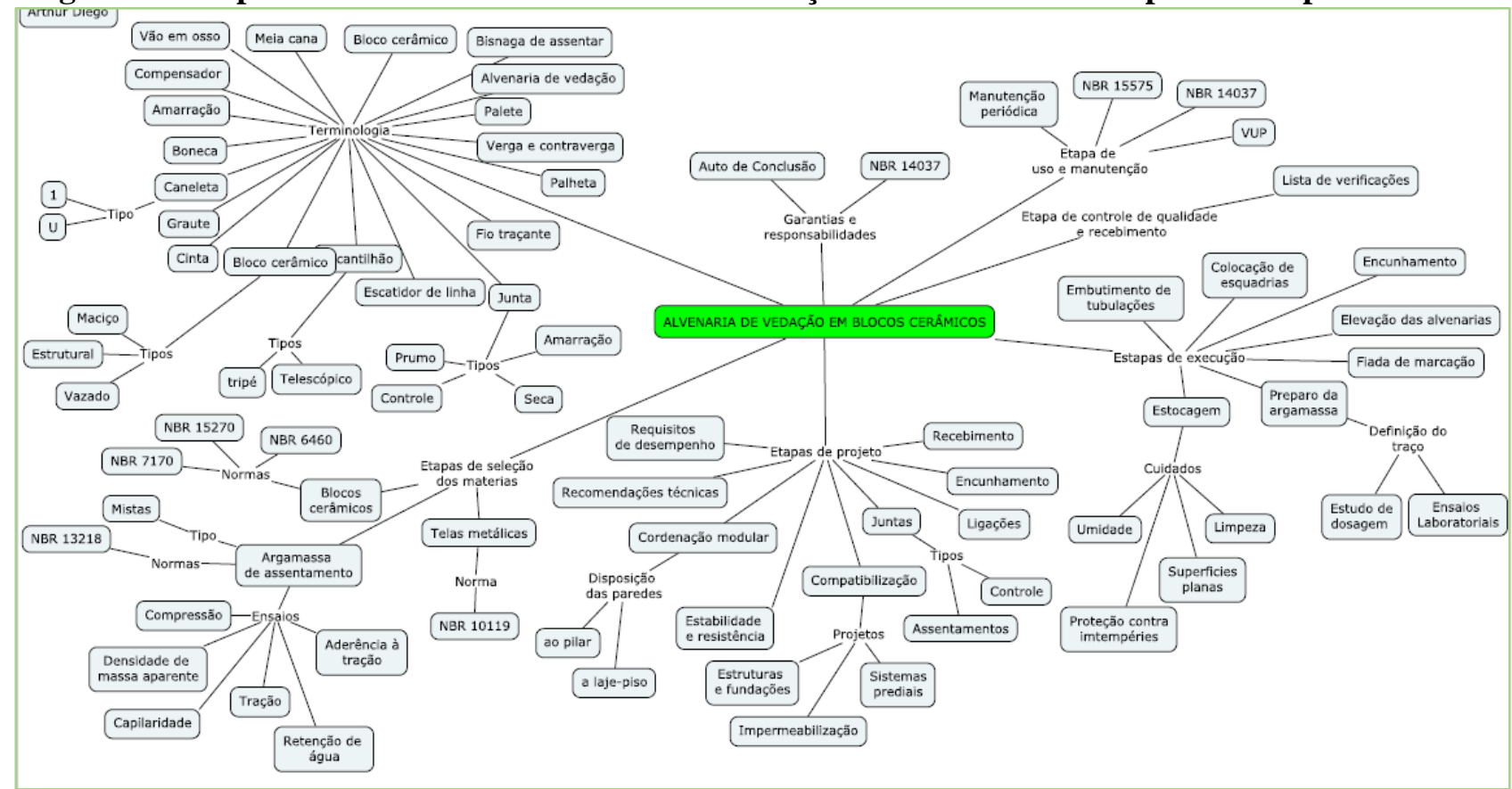

Fonte: Aluno A da disciplina Tecnologia das Edificações II (2017).

Figura 8 - Mapa Conceitual sobre Alvenaria de Vedação de Bloco Cerâmico produzido pelo aluno D

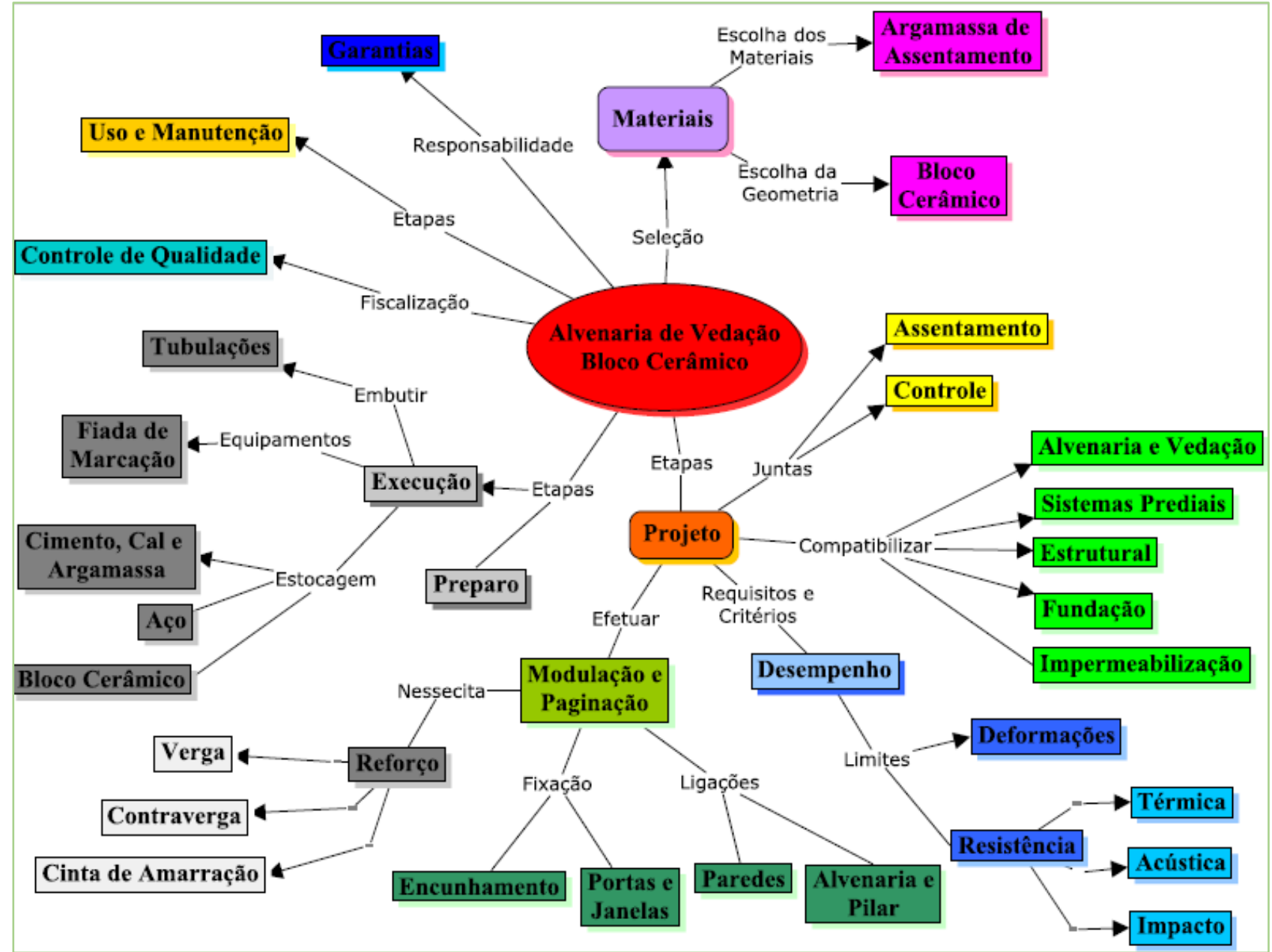

Fonte: Aluno D da disciplina Tecnologia das Edificações II (2017) 
Os mapas foram analisados essencialmente de forma qualitativa, buscando-se interpretar a informação dada pelo aluno que evidenciasse sua aprendizagem significativa. $\mathrm{O}$ mapa conceitual considerado BOM foi aquele que fez uma abrangente relação de conceitos e estabeleceu adequadamente as suas interrelações. O mapa REGULAR foi aquele no qual o aprendiz não conseguiu verificar as conexões existentes entre os conceitos propostos.

No uso do mapa conceitual como recurso de aprendizagem, percebeu-se que cerca de $70 \%$ fizeram mapas ACEITOS. Como processo avaliativo, cerca de $90 \%$ dos mapas apresentados puderam ser considerados ACEITOS. Atribui-se essa melhoria de classificação a dois fatores; são eles: os alunos já haviam feito um mapa conceitual previamente e o professor já havia discutido o conteúdo em sala de aula

\section{CONCLUSÕES}

Verificou-se com sucesso a utilização do mapa como recurso de aprendizagem e como forma de avaliação, tendo em vista a evolução na apropriação de significados no processo de aprendizagem nessa área da Engenharia Civil. Os alunos, após compreensão do que é um mapa conceitual, fizeram sua primeira concepção de um conteúdo sem nenhuma explanação prévia, apresentando dificuldade de encontrar as relações entre os conceitos gerais e específicos, levando a autonomia na pesquisa sobre a temática e construindo seu conhecimento, para obtenção de relações esperadas pelo professor. No segundo momento, após aulas expositivas sobre Vedações Verticais, receberam um texto sobre um conceito específico "alvenaria de vedação em blocos cerâmicos". A partir daí já elaboraram mapas conceituais com relações entre os conceitos mais próximas do esperado pelo professor, incluindo apresentação gráficas mais claras.

Sentiu-se a necessidade de mais tempo dedicado à aplicação dessa metodologia, para melhor explorar a explicação dos significados atribuídos aos conceitos trabalhados nas duas situações. Tal situação vai ao encontro da necessidade de ajuste do currículo de formação do engenheiro para as metodologias de aprendizagem ativa.

Como desdobramento, sugere-se verificar a percepção dos alunos sobre os procedimentos pelos quais passaram e se houve emprego dessa metodologia para outras disciplinas do curso. Além disso, o mapa conceitual pode ser aplicado como forma de avaliação do conteúdo programático das disciplinas, visando a melhorar seu desenvolvimento e contribuição para formação profissional dos futuros engenheiros.

\section{REFERÊNCIAS}

BORGES, T. S.; ALENCAR, G. Metodologias ativas na promoção da formação crítica do estudante: o uso das metodologias ativas como recurso didático na formação crítica do estudante do ensino superior. Cairu em revista, Salvador, v. 3, n. 4, p. 119-143, 2014.

CAÑAS, A. J.; NOVAK, J. D. The Origin and Development of Concept Maps (2009). Disponível em: <https://cmap.ihmc.us/docs/origins.php>. Acesso em: 16 jan. 2018.

GERBAUER, F. Planejamento e gestão de obras: um resultado prático da cooperação técnica Brasil e Alemanha. 1.ed. Curitiba: CEFET-PR, 2002.

GODOY, C. E. Estratégia para elaborar um bom Mapa Conceitual. Disponível em: <http://www.cecgodoy.pro.br/sc2008/index.p hp?option=com_content \&view $=$ article $\& i d=57$ :estrategia-para-elaborar-um-bom-mapaconceitual\&catid $=40$ :mapasconceituais\&Itemid=58>. Acesso em: 19 out. 2017.

MOREIRA, M. A. Mapas conceituais e aprendizagem significativa. Disponível em: $<$ https://www.if.ufrgs.br/ moreira/mapasport.p df>. Acesso em: 30 abr. 2018.

PINTO, G. P. R.; SOARES, L. R.; SANTOS, D. M. R.; BURNHAM. Mapas conceituais apoiando a religação de saberes na formação do 
engenheiro. Anais... XXXIX Congresso

Brasileiro de Educação em Engenharia, 2011, Blumenau. Santa Catarina, 2011.

TAVARES, R. Construindo mapas conceituais. Ciências \& Cognição, Rio de Janeiro, v. 12, n. 1, p. 72-85, 2007.
THOMAZ, É. et al. Código de práticas $\mathbf{n}^{\circ} 01$ : alvenaria de vedação em blocos cerâmicos. São Paulo: IPT - Instituto de Pesquisa Tecnológicas do Estado de São Paulo, 2009.

\section{DADOS BIOGRÁFICOS DOS AUTORES}

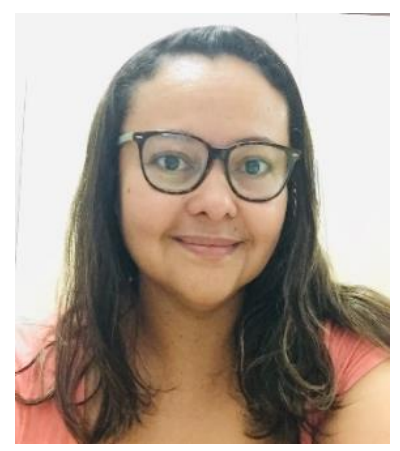

Leonete Cristina de Araújo Ferreira Medeiros Silva - Doutoranda em Engenharia Química pela Universidade Federal do Rio Grande do Norte UFRN. Mestre em Engenharia Sanitária (2008), especialista em Engenharia de Segurança do Trabalho (2009) e Engenheira Civil (2005), pela Universidade Federal do Rio Grande do Norte - UFRN. Tecnóloga em Meio Ambiente pelo Instituto Federal do Rio Grande do Norte - IFRN (2002). Atualmente é Professora Assistente do Departamento de Engenharias na Universidade Federal Rural do Semiárido - UFERSA - Centro Multidisciplinar de Caraúbas, ministrando aulas para os cursos de Bacharelado em Ciência e Tecnologia e Engenhara Civil. Possui experiências profissional em Fiscalização de obras públicas, Construção Civil, Licenciamento Ambiental, Avaliação de Imóveis e Ensino (Meio ambiente, Segurança do trabalho, Desenho e Construção civil). 